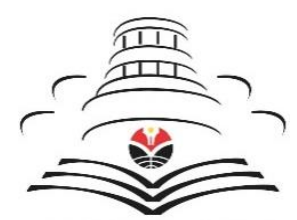

JURNAL UPI
INDONESIAN JOURNAL OF APPLIED LINGUISTICS

Vol. 9 No. 1, May 2019, pp. 58-66

Available online at:

http://ejournal.upi.edu/index.php/IJAL/article/view/16141

\title{
Designed-in and contingent scaffolding in the Teaching Practice Groups model
}

\author{
David Mallows \\ University College London, Institute of Education, Department of Communication, Culture and Media, 20 Bedford \\ Way, London WC1HOAL, United Kingdom
}

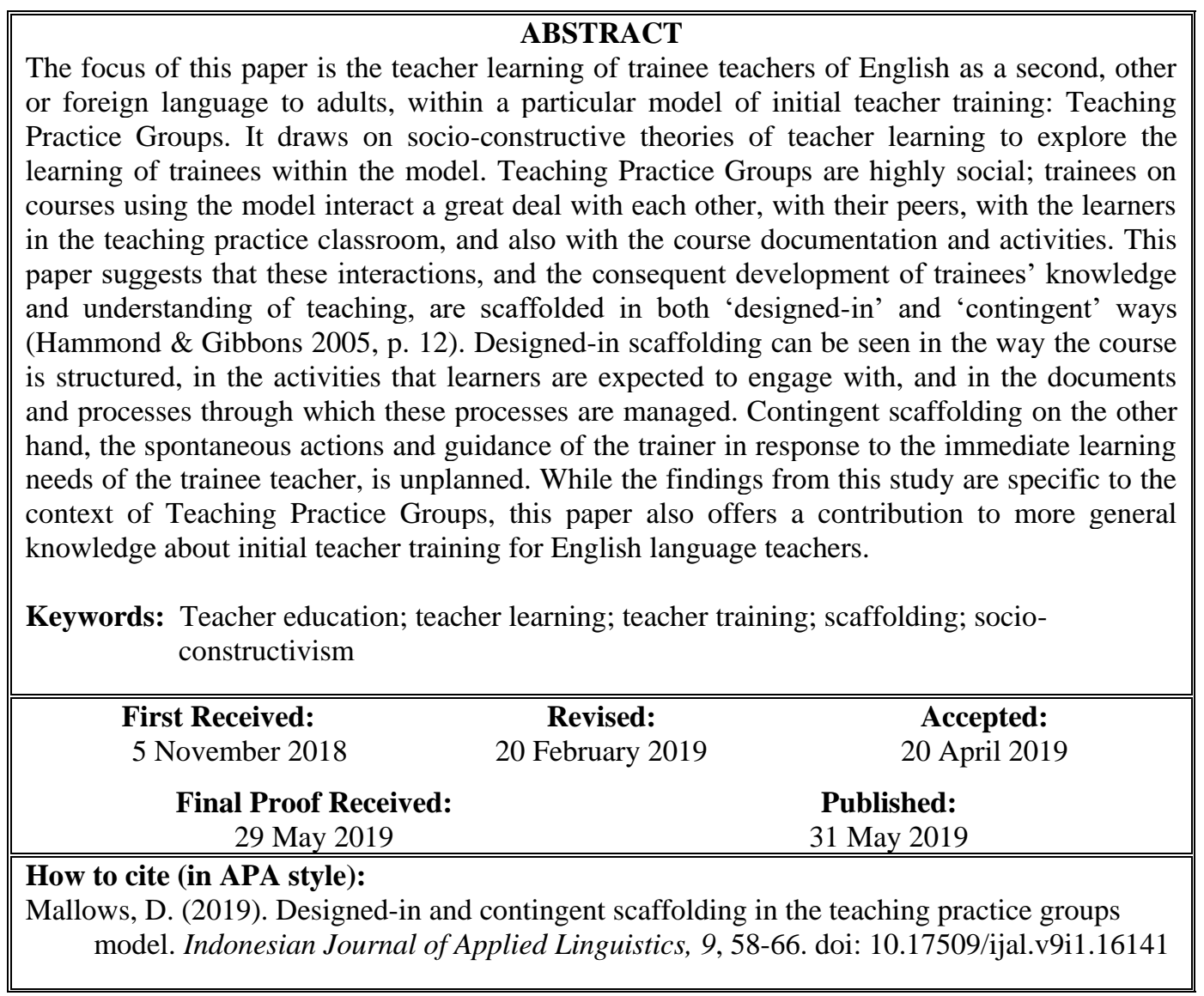

\section{INTRODUCTION}

In teacher education research, there is a great deal of concern about the knowledge base of teacher education, the content, theories, practices and skills that will be of use to new teachers as they develop into their new role and grow as professionals. This is also true in terms of policy, as policy makers stipulate the regulations that govern the work of teachers and of individual teacher trainers as they design courses. However, while engagement with issues of what teachers need to know is important, and research in this area is welcome and has contributed greatly to our understanding, it can be argued that what teachers need to know is actually a secondary issue. It may be that what is of more urgent concern for teacher educators and others concerned with professional development of new and experienced teachers is how such knowledge, however that knowledge is defined and categorised, is effectively acquired.

In this paper I will present data from a study of a particular model of initial teacher training, Teaching Practice Groups, which is used with trainee teachers of English as a second, other or foreign language to adults.

The study looked at the main factors in the organisation and implementation of the Teaching Practice Group model and their impact on the learning of the trainee teachers. In attempting to address this, of central concern is what is known about the way in which 
teachers learn to teach. Questions about how teachers process, assimilate and use new knowledge are of great importance. In this paper I will employ concepts from socio-constructivism as a framework through which to understand teacher learning within the Teaching Practice Group model.

Socio-constructivism suggests that the cognitive development that takes place through learning is an interactive process (Johnson, 2009) by which we learn through engaging with others in social processes. An implication of this is that teacher learning should be an active process achieved through participation in the context of practice - the classroom. The particular model of teacher training that is the focus of this paper, Teaching Practice Groups, is highly social. Trainees constantly engage with others - trainers ${ }^{i}$, peers and learners - in the social context of planning for and acting within the classroom. Accordingly, social conceptions of learning, in which the creation of knowledge is situated within a social context and is dependent on social relationships which learners build with their peers and teacher, provide a useful theoretical framework through which to examine data from this context. Drawing on concepts from socio-constructivism allows for such learning to be conceptualised as a mediated process, scaffolded by the structures, processes and agents of the Teaching Practice Group model.

This paper begins by describing the three-stage cycle of the Teaching Practice Group model. It then goes on to present the key concepts of socioconstructive theories of learning which provide the framework for analysis, before drawing on interviews from trainers and trainees with experience of Teaching Practice Groups, as well as observation data, to exemplify the concepts discussed.

\section{Teaching Practice Groups}

In this section I will describe in detail the Teaching Practice Group process in order to identify the elements and procedures experienced by trainees and used by trainers on courses using this particular approach to teacher training.

Teaching Practice Groups is a model of teacher education that has been used extensively in the field of English language teaching, in particular on the Cambridge CELTA course and its predecessor the RSA CTEFLA. Cambridge ESOL describes the purpose of Teaching Practice Groups as providing opportunities 'for candidates to show that they can apply theory to practice in classroom teaching' (Cambridge ESOL, 2018).

Teaching Practice Groups give teacher trainees on initial teacher training programmes the opportunity to work with real learners in a semi-controlled environment. It is an intensive model which provides a high level of support to the trainee and gives the trainer the opportunity to model good practice and to make connections for trainees between the practical experience of being in a classroom with real learners and the theoretical input and readings that make up the rest of the course.

The Teaching Practice Group model is made up of a cycle of planning, teaching, and feedback revolving around a shared group of learners. Within each cycle trainees' engagement with teaching is organized and guided by the procedures followed and the documents used by trainees to prepare for, carry out and reflect on teaching. The documents include formal lesson plans, self-evaluation forms to be completed by trainees following their teaching, written feedback forms on observed teaching completed by the trainer, and observation tasks carried out by trainees while observing. This paper will suggest that these documents, and the actions of the trainer in interacting with trainees around the shared class, mediating trainees' learning, guiding and focusing their attention to relevant elements of the teaching and learning process.

One of the distinctive features of the teaching practice group model is the high number of observers in the classroom. When there are six trainees in the group, five of these, plus the trainer sit at the back of the class observing and taking notes. This is in contrast to the general culture of closed classrooms in which it is rare for there to be observers in a classroom other than for inspections or other formal assessments of the teaching (Copland, 2008).

The use of a group of learners, a Teaching Practice Class is central to the Teaching Practice Group model. The class act as 'guinea pigs' for the trainee teachers, allowing them to experience real teaching as part of their learning process The Teaching Practice Class is usually made up of adults who have been recruited specifically for the purpose and who do not pay for the course. In a sense they volunteer for the class, with the understanding that they will be taught by a group of trainees, rather than by a professional, trained teacher.

Not only do trainees share the group of learners, giving them a common set of challenges in terms of designing and delivering learning that takes account of the learners' levels, prior knowledge, learning styles and personalities, but they also plan for the sessions together. Planning is an important part of the Teaching Practice Groups process - joint planning sessions are part of the formal timetable of the course and generally take place in a communal area where course books, grammar books and resource books are available as well as pens and scissors and a photocopier. Here trainees sit together and discuss their learning aims, brainstorm ideas, select and design resources, and sketch out rough drafts of their lesson plans. This environment encourages sharing of ideas, resources and even craft skills.

Within any particular planning session trainees may be at different stages, with some about to teach and others in the initial stages of planning for a class the following day. The planning discussion provides an opportunity to fine tune elements such as timing of activities; to better understand any language items that require attention; and to anticipate any difficulties for 
the learners or the teacher. Exploratory discussion is also common, with the trainer reacting to trainees' initial ideas and suggesting activities and resources for them to consider.

Trainees are required to coordinate their planning to ensure coherence across the whole teaching session as well as within their own individual time 'slot'. They are made aware of the importance of their individual 'lesson' building on previous work with the learners and preparing them for whatever the next trainee has planned. This is achieved, or not, largely through the shared lesson planning sessions which encourage and facilitate such coordination. Requiring trainees to work together in this way also encourages them to look beyond their own lesson and to discuss and contribute to the development of their fellow trainees' plans, for which they receive reciprocal support.

As well as planning jointly, trainees also teach the same class and observe each other teaching this shared group of students. The opportunity to watch others teaching is central to the Teaching Practice Groups model. By giving trainees the luxury of observing 'their' group without being in front of the class, with responsibility for managing the learning, their attention can be focused on the teaching and learning activities taking place and they can be encourage to reflect on what they can gain from these in terms of their own approaches to teaching.

Constructive feedback on teaching practice observations is an essential part of any teacher-training programme (Hyland \& Lo, 2006). Trainee teachers need clear and honest feedback to help them reflect on their strengths and act on their weaknesses progressively as they develop their expertise. The feedback sessions in the Teaching Practice Group model take place immediately after the taught session and are used to reflect and evaluate on the teaching and begin the process of planning for the next session. The trainees watch each other teach and discuss the interactions that they all have with the same group of learners in the same learning context.

Unlike the majority of teaching practice feedback sessions, which are dyadic with one trainer and one trainee, feedback within the Teaching Practice Group model involves between three and six trainees as well as the trainer Copland (2008). A number of the trainees participating in the feedback will not have taught in the teaching session under discussion, while others will have.

As well as taking part in the oral feedback session, trainers also complete a written feedback form. This is used to reinforce messages from the oral feedback and to ensure that the trainee and the trainer have a shared record of the discussion.

The three elements of the Teaching Practice Groups model (planning, teaching/observation, feedback) should work as a seamless set of iterations, a cycle revolving around the language learning of a group of students and driven by the need to complete, document and learn from, the practical task of teaching them. Teacher learning within this cycle is situated within teaching itself and is facilitated by the intensive nature of the interactions that trainees experience: between the trainees themselves in planning and feedback; between the trainees and the trainer; between the trainees and the teaching resources they draw on to plan and to teach; between the trainees and the course documentation that they complete; and of course between the trainees and the students in the Teaching Practice Group. These constant, structured interactions around the teaching process are central to the model of teacher learning within the Teaching Practice Groups model.

\section{A socio-constructivist model of learning to teach}

Constructivism is an epistemological position that posits that it is not possible to separate the knower from what she knows (Crotty, 1998). This belief in individual interpretations of reality has been influential in education and has been drawn on extensively in the development and design of teacher training courses. Constructivism does not see knowledge as an external, independent entity with an absolute value, such as can be contained in a textbook. It rejects the idea that meaning can be passed on to learners either directly or via symbols or that learners can incorporate exact copies of their teacher's understanding for their own use.

Constructivists argue that acquiring new knowledge and skills involves more than receiving and memorising new content (Richardson, 1997, p8). Instead, constructivism focuses on the social nature of cognition, arguing that learners require the opportunity for contextually meaningful experience through which they can search for patterns, raise their own questions, and construct their own models. Thus, learning requires engagement with others as well as with learning content. And it is through social interaction around the learning content that learning takes place.

Socio-constructivism suggests that our understanding of the world is produced through engagement with others in social activities, and that this interaction contributes to our learning (Richardson, 1997, p. 7). Socio-cultural understandings of learning are often used in opposition to cognitive theories, rejecting what are seen as positivistic theories which view learning as “...an internal psychological process isolated in the mind of the learner and largely free from the social and physical contexts within which it occurs" (Johnson, 2006, p. 238).

Vygotsky (1978) emphasises the fundamental role of social interaction in the development of cognition. For Vygotsky individual development cannot be understood without reference to the social and cultural context within which it is embedded. He proposes that complex mental functions are first an interaction between people and then subsequently become a process within individuals, with this transition from external operation to internal development central to changes in the understanding of individuals. 
A socio-constructivist model of learning suggests that individual cognitive development is mediated through social interaction in a particular cultural environment. Vygotsky saw mediation as a process through which the mediator, often a parent, peer or teacher organises and interprets the world for the benefit of the learning of the child (Seng, 1997). It can.be argued that learning to teach is mediated through the activities carried out by the trainees and by the structures and requirements of those activities within a particular teacher education programme. The course should provide contextually meaningful experience through which trainees can actively engage with others, as well as with learning content.

For Vygotsky it was important to measure in learning not just what a child could do in a test working alone, but also what the child could do with the support of another person, usually an adult, but also possibly a more knowledgeable peer (Hammond \& Gibbons, 2005, p. 8). He called the difference between what a child could do alone and with support, the distance between the actual independent development level and the potential development level under the guidance of or in collaboration with peers, the zone of proximal development. He saw learning as a continual movement, from the current intellectual level to a higher level, which more closely approximated that individual's potential. He saw this movement as occurring as a result of social interaction in this zone of proximal development (Chaiklin, 2003, p. 40).

For Vygotsky, the purpose of teaching was thus to create situations and processes that support the child in moving across this gap so that they are able to carry out the task without the support of the 'other'.

Acceptance of the concept of the zone of proximal development implies that without the assistance of the more knowledgeable other the learner will not be able to bridge the gap between their actual and potential levels of understanding. However, it is important to note that it is not the knowledge of the more knowledgeable other that is of significance in supporting the learner in moving through their zone of proximal development. For Vygotsky, it is their support within the mediation process that has the impact.

In this paper I argue that the mediators in the Teaching Practice Group model are the people and the structures of the course, and that these guide trainees to notice elements of the teaching and learning process in ways that are in fluential in their learning to teach.

\section{Scaffolding}

Scaffolding is a key concept within the socioconstructivist approach to learning (Richardson, 1997). Mediators guide trainees to notice and consider particular elements of the teaching and learning process. In this sense we can say that they scaffold the learning of the trainee teachers. The concept of 'scaffolding', while closely related to Vygotsky's concept of mediated learning, and the zone of proximal development, was not a term that he actually used. However, it can be seen as 'an inherent part of his theory of learning as collaborative and interactionally-driven' (Hammond \& Gibbons, 2005, p. 7). The term scaffolding itself emerged from the work of the educational psychologist Bruner (Wood, Bruner, \& Ross, 1976), who described it as support coming from more knowledgeable others that helps learners to internalize what is being learned. It should be appropriate to the learner's zone of proximal development (ZPD), their current and potential level of development. For each person this will be different depending on their prior experience and pace of adaptation and learning.

Hammond and Gibbons (2005, p. 8) describe scaffolding as 'task-specific support, designed to help the learner independently to complete the same or similar tasks later in new contexts. It can be provided by any external source that supports the learner in working beyond their current independent development level. While the most important source of support for both Bruner and Vygotsky was found in collaboration with others, structured activities, worksheets and writing frames can all act as scaffolds. In teacher education the scaffolds are provided by the trainers and also fellow trainees as well as the course structure with its documentation and assessment directing trainees' attention and supporting them in increasing their understanding.

Hammond and Gibbons (2005) suggest that it is useful to distinguish between two distinct forms of scaffolding - 'designed-in' and 'contingent'. They argue that both have the same purpose of supporting the learners through their zone of proximal development, but that while the former is pre-planned, the latter is not.

Designed-in scaffolding can be seen in the way the course is structured, in the activities that learners are expected to engage with and the documents and processes through which these processes are managed (Hammond \& Gibbons, 2005, p. 12). In a teacher training course, the pro-formas that trainees are asked to complete to plan for and record their work on the course, such as lesson plans, provide designed-in scaffolding. Such pro-forma supports the trainee teacher in developing their understanding of the teaching and learning process by focusing their attention on certain aspects of the teaching and learning process. In the case of the lesson plan, this scaffolds trainees' understanding of planning, ensuring that they consider elements that the course team thinks are of relevance when planning a lesson.

Written assessments within teacher training courses can also be understood as designed-in scaffolding, directing trainees to reflect upon specific elements of the teaching and learning process identified as significant by the course team.

Contingent scaffolding on the other hand is unplanned and usually provided by the trainer. It is the spontaneous actions and guidance of the trainer in response to the immediate learning needs of the trainee teacher. Much contingent scaffolding in teacher training courses comes in either the input sessions or in 
feedback. In the input sessions the trainer and the trainees discuss concepts and processes relevant to teaching and learning and the trainer responds to and guides the growing understanding of the trainees in a contingent manner. Much of this responsive work is not pre-planned, even though the activities and materials used are likely to be.

Hammond and Gibbons (2005) consider both contingent and designed-in scaffolding as essential elements of any structured learning process. However, they suggest that it is in combination that they are most effective, with the designed-in features contextualizing the contingent scaffolding, which may otherwise '...become simply a hit and miss affair that may contribute little to the learning goals of specific lessons or units of work' (Gibbons \& Hammond, 2005, p. 20). They argue that the designed-in level enables the use of contingent scaffolding and that both support students to work within their zone of proximal development.

In the following section I will discuss ways in which the Teaching Practice Group model works to actively engage trainees with the content of learning to teach, exploring in particular the mediators of the trainees' learning. I will suggest that the active engagement of trainees with content, the world of teaching and learning, is mediated by the collaborative activities of the Teaching Practice Group model; the designed-in scaffolds of the course documentation and activities; and the contingent scaffolding of the trainer.

\section{METHOD}

This paper reports on one element of a broader study of teacher learning. The aim of the study was to increase understanding of the process of learning to teach, situated in the particular context of Teaching Practice Groups used with prospective English language teachers. The study collected empirical data in order to better understand the ways in which Teaching Practice Groups facilitate teacher learning. The data collected was qualitative in nature. The qualitative approach to research seeks to describe, understand, and explain specific issues. Schofield (1993) suggests that qualitative studies can lead to 'an increased awareness of the importance of structuring qualitative studies in a way that enhances their implications for the understanding of other situations' (p. 109). While the findings from this study are specific to the context of Teaching Practice Groups, the study also offers a contribution to more general knowledge about initial teacher training for English language teachers.

\section{Data collection}

The data was drawn three different sources: interviews with teacher trainers and trainee teachers reflecting on their experience with Teaching Practice Groups; observations of the three-stage cycle of the Teaching Practice Group model; and documents used as part of the process.
I carried out semi-structured interviews with seven trainers and seven trainees. Semi-structured interviews "....allow depth to be achieved by providing the opportunity on the part of the interviewer to probe and expand the interviewee's responses" (Hatch, 2002). I interviewed seven trainers with extensive experience of the use of Teaching Practice Groups and 7 newly qualified teachers who had just completed an initial teacher training course in which Teaching Practice Groups were employed. Purposive sampling (Palinkas et al., 2015) was used to select both sets of interviewees in order to maximize the validity of the data collected. I have worked on CELTA courses off and on for the last fifteen years and in that time I have worked with many different trainers. I also helped introduce Teaching Practice Groups to a PGCE course at my own institution and through that made contact with trainers working outside the CELTA. Accordingly, gaining access to interviewees was a fairly straightforward process.

The trainers were selected on the basis that they met certain key criteria. The first, and most important criterion was that they had extensive experience of the use of Teaching Practice Groups. All of the interviewees had used the model while working on CELTA courses. I also used purposive sampling to select trainees for interview. Firstly, I wanted to interview people who had been on the same course in order to remove possible variation in the way the Teaching Practice Group had been run. I also felt that in order to ensure the validity of the research process it was important that interviewees had recently finished their course so that the experience was still fresh in their minds and they were able to reflect on it in the interview. The final factor was that I wanted the interviewees to have had as little teaching experience as possible prior to beginning their course.

I collected observation and documentary data from a four-week teacher training course using the model. The observation data was in the form of audio recordings and field notes of trainee and trainer interactions across the three-stage cycle of the Teaching Practice Group model. The documentary data included lesson plans, self-evaluation forms, trainer feedback forms, and classroom observation tasks.

\section{Data analysis}

An interpretivist stance was taken to the analysis of the data collected. Interpretivists seek to understand the complex world of lived experience from the point of view of those who live in it (Guba \& Lincoln, 2005). The interpretivist philosophical stance has at its heart the idea that what we observe does not have intrinsic meaning, rather that the meaning of the objects we study "lies in the actions that human beings take toward them" (Denzin, 1978, p. 7). Thus, as all meaning is socially constructed, it makes no sense to attempt to isolate the observed facts from our own interpretation of them - the researcher is part of what is being researched and cannot be separated. His or her interpretation of the phenomenon in study will be subjective. 
Interpretivist research is concerned with process (the why and the how) as well as outcome or facts (the where, the what, the who, and the when). It focuses on descriptions and interpretations of social contexts in order to gain a deep understanding of human opinion and behaviour (Schwandt, 1994).

The importance of studying the phenomena of Teaching Practice Groups in the social context in which they take pace, and through the lived experience of participants, informed selection of data. This comes from three sources: interviews with trainers and trainees, observation of the Teaching Practice Group process, and documents collected from sites of learning. The three sources of data have been triangulated (Cohen, Manion, \& Morrison, 1986, p. 254) to increase the validity of the findings.

As well as informing the development of the interview frames for the trainers and trainees, the main use of the observation and documentary data within the analytical phase was to contextualize understandings gained through the interviews. It was used to construct a robust and consistent model of the three-stage Teaching Practice Groups cycle. This allowed for the anecdotes gathered from the interviewees to be contextualized in a consistent manner and for links to be made between these.

\section{Ethics}

In collecting and analysing the data on which this paper is based, I followed the BERA Ethical Guidelines for Educational Research ${ }^{\text {ii }}$. The main ethical issues to be addressed in this study were informed consent and confidentiality/anonymity.

\section{Scaffolding of teacher learning within the planning stage of the Teaching Practice Groups model}

As discussed above, scaffolding, closely related to Vygotsky's concept of mediated learning, supports learners in moving through their zone of proximal development, the distance between what they can do alone, and with support. Interaction in this zone is supported by scaffolds, 'task-specific support', designed to help the learner independently to complete the same or similar tasks later in new contexts' (Hammond \& Gibbons, 2005, p. 8).

Learning is most commonly scaffolded by the people around us, by someone with greater knowledge who can help us bridge the gap between what we know at the time and the target knowledge. In teacher training, the scaffolds are provided by the trainers and also fellow trainees. However, learning can also be scaffolded by the course structure with its documentation, processes and assessment directing trainees' attention and supporting them in increasing their understanding.

Above I identified two distinct forms of scaffolding - 'designed-in' and 'contingent'. Both have the purpose of supporting the learners through their zone of proximal development, but while the former is pre-planned, the latter is not.
Within the data collected as part of this study elements of both designed-in and contingent scaffolding can be identified. In the next section I will draw on the data collected from the planning stage of the Teaching Practice Group model in order to give examples of ways in which teacher learning in the model is guided by designed-in scaffolding and supported contingently through the advice and guidance of the trainer.

\section{Teaching Practice points}

In the initial stages of the Teaching Practice Group model, the teacher trainer takes much of the responsibility for assessing the shared group of learners, drawing up an overall scheme of work and suggesting specific activities and resources for each teaching slot. As the trainees gain in experience and confidence, they take on more responsibility for planning; they remain under supervision of the teacher trainer, but the latter's active contributions are gradually reduced. Thus, trainees' developing understanding of the planning process is scaffolded by the trainer.

The planning, particularly in the early stages of the course is guided by the trainer, through the setting of Teaching Practice (TP) points. TP points are a description of what the trainee should teach in their allocated slot. They may cover just the language items / skills to be taught, but may also include more detailed suggestions on process or resources to be used. The TP points are chosen to be coherent with the other slots in the class and with the learning needs of the students.

At the beginning of the process the TP points are generally detailed, giving trainees clear guidance on the specific language and / or skills that they are required to work on with students in their particular teaching slot. The detailed specification of Teaching Practice Points is gradually reduced as the course progresses, until trainees are just given very general lesson aims, such as 'give them some speaking practice', 'do some reading with them' or 'revise the past simple'. This withdrawal of guidance on planning is intended to encourage trainees to become more independent and to make their own decisions about how to achieve their aims.

The use of TP points reveals both designed-in and contingent scaffolding. Designed-in, as the allocation of TP points is part of the Teaching Practice Group process, but also constringent, in that the trainer can align the TP points to the perceived stage of understanding of a particular trainee.

The scaffold provided by TP points was commented on by a number of the trainees interviewed as of great importance in the initial stages of learning to teach. As would be expected, they felt that without the TP points they would have found it far more daunting to approach planning their first lessons. They also commented on the learning that discussion of the TP points could lead to.

It was fascinating to see the way she (the trainer) broke teaching down into little bits that we could prepare for without it becoming disjointed for the learners - in fact it was the opposite, far more coherent. (Trainee 2) 
For this trainee, the TP points allowed her to see more clearly how the learning should be structured, both in terms of the focus of each part, and its connection to the other parts.

\section{The lesson plan}

Planning within the Teaching Group Practice model is informed by the teaching practice points and is structured by the formal written lesson plan that trainees are required to produce. The lesson plan guides trainees through the planning process by signposting to them what it is necessary to consider when planning a lesson, such as the target language or the interaction patterns between learners. For example, using a lesson plan which requires trainees to specify the interaction patterns in the planned class will ensure that the trainee considers the importance of this in planning their lesson. Without the designed-in scaffold of the lesson plan they would be less likely to notice if the interaction patterns within their planned activities were, for example, repetitive. Trainees then need to produce a considered and thoughtful response, in the form of a lesson plan.

Lesson plan pro-formas differ from one teaching centre to another, but generally share a number of common features and mean that trainee teachers, in their planning, are forced to consider certain aspects of the teaching and learning process. The lesson plan proformas used in the courses observed were introduced in input sessions in which the individual elements (e.g. aims, target language, stages, timing, interaction patterns, assessment, etc.) were presented to and discussed with trainees. Most lesson plan pro formas ask for trainees to specify the aims and objectives of the class and sometimes they are also required to state their aims for each stage of the lesson. As well as outlining the aims, most lesson plans require a chronological description of the procedure the trainee is planning to use. The planned activities are generally divided into discrete 'stages', each with its own aim, timing, description of procedure and expected interaction patterns. Assessment of learning and materials to be used may also be part of the lesson plan pro forma.

Trainees' planning discussions focus on solving problems - what to do, when and how. Their attention is focused on the coherence of the content they are proposing to work with, and the variety and appropriateness of inputs and interactions that they have included in the lesson plan. The lesson plan scaffolds their developing understanding of the nature of each element and its interplay with the other elements of the lesson.

The guidance provided in the planning process through TP Points and a set lesson plan pro-forma was apparent in each of the courses observed and was reflected in the experience of the interviewed trainers. One trainee described how the imposition of the requirement to explicitly and publicly describe the stages of her activities/lessons in the form of a lesson plan has helped her to 'see' the classroom more effectively, noting the need for a coherence student experience.

"I think if I was going to do reading with a class, naturally you'd bring in the different aspects, but I wouldn't put it in - I think the structure's very useful, I think it would take you a very long time to work out that structure or fall into that structure. I'm a bit all over the place anyway, I didn't know when I first started doing the teaching practice, I was a bit stupid, I didn't realise you were meant to be using all these structures, and I spent ages trying to put classes together, and them being like "There's no structure", because I was trying to, you know, I was grouping things into like, an order, but not the same order. Doing one topic, but all the different bits of the topic, rather than doing the different skills. It's hard to describe what I mean, like the board stage and the eliciting stage might be mixed together, so when I elicit this, I don't put it on the board, instead of eliciting everything and then putting everything on the board." (Trainee 8 )

For trainee 8 the lesson plan acted as a designed-in scaffold, focusing her attention on specific elements of the teaching and learning process.

\section{Personal development goals}

In the Teaching Practice Groups observed trainees were also required to outline their own personal development goals within each lesson plan. These could be drawn from feedback on previous teaching slots and are intended to identify what the trainee wishes to improve in their teaching. One trainee described how she used these to ensure that she did not repeat past mistakes:

"... at the bottom of my lesson plan I have review questions for myself, and that would usually include, I think, there was one point about addressing the whole class rather than individual groups, because that was something that had come up a couple times, so I put that on there, as a reminder to see if I had actually done that. And that, I think, worked, because by the final lesson, I was talking to everyone." (Trainee 1)

Here again we can see that the designed-in scaffold of the personal development goals focused this trainee's attention on specific elements of the teaching and learning process, supporting her in developing her own understanding.

During the planning process the trainers were available as a resource, offering advice on structure and timing of activities and providing suggestions for resources. In engaging with trainees around the lesson plan documentation the trainers may also work contingently to guide trainees in identifying personal development goals that are appropriate for their stage of learning to teach. The advice and guidance given by the trainer during the trainees' planning process can be seen as contingent scaffolding. It is unplanned and comes in response to the immediate learning needs of the trainee. It is contingent; it depends on the context of the individual trainee and the issue under focus. Trainers reported that they gradually reduced this contingent scaffolding as the trainees gained more experience and 
became more confident in their own ability to construct a rational teaching plan.

The cyclical nature of the Teaching Practice Group process is another example of designed-in scaffolding. Trainees were able to identify an explicit relationship between the feedback that they received on their teaching and the group planning that they would engage in following the feedback session in preparation for their next teaching slot. A number explained how the feedback that they received would influence their planning of subsequent teaching slots. At times this was through explicit individual recommendations to trainees about given by the trainer. Such 'development points' were often included in the written feedback given to trainees and progress in meeting them would be checked through the next observation. In other cases, the initiative to focus on a particular point came from the trainee in response to comments made to the whole group of to another trainee.

... there was one point about addressing the whole class rather than individual groups, because that was something that had come up a couple times, so I put that as a reminder to see if I had actually done that. And that, I think, worked, because by the final lesson, I was talking to everyone. (Trainee 1)

Contingent scaffolding on the other hand is unplanned and occurs in the moment-to-moment interaction between trainer and trainee. It is the spontaneous actions and guidance of the trainer in response to the immediate learning needs of the trainee teacher. Much contingent scaffolding in teacher training courses comes in either the input sessions or in feedback, in the form of oral feedback on teaching, comments on a lesson plan, suggestions for alearning activities, or signposting to reading material. It can also be in written form. For example, the written feedback that the trainer gives the trainee after each teaching session is contingent - it depends on the context of the individual trainee and the issue under focus.

Designed-in and contingent scaffolding can be used in combination. The designed-in elements enable more effective use of contingent scaffolding by the trainer. Much of the contingent scaffolding observed took place around the designed-in scaffolds within the lesson planning, observation, and feedback cycle. Designed-in elements such as the setting of Teaching Practice points by the trainer, the use of a pro-forma lesson plan, observation tasks and a self-evaluation form, contextualize the interventions of the trainer and help trainees in making best use of the support of the trainer.

\section{CONCLUSION}

Data collected as part of this study suggests that teacher learning within the Teaching Practice Groups model is highly social, situated in the classroom, and scaffolded. A key feature of the model is that it provides teacher training in which learning to teach is grounded in, and centred on, the language classroom. This creates a rich and stimulating experience for trainees and one that can be used by trainers to effectively support trainees in learning to teach.

The Teaching Practice Group model allows trainers to scaffold the learning of trainees, supporting them in moving through and beyond their zones of proximal development. Designed-in scaffolding is inherent in the processes of the course and the documentation used by trainers and trainees, and can be seen in the way the course is structured, in the activities that learners are expected to engage with and the documents and processes through which these processes are managed. These designed-in, structural elements of the model provide contextualization for the contingent scaffolding provided by the trainer in the form of advice and guidance to individual trainees as they navigate the course.

\section{REFERENCES}

Cambridge ESOL. (2018). CELTA Certificate in teaching English to speakers of other languages syllabus and assessment guidelines (5th ed.). Cambridge ESOL: Cambridge

Chaiklin, S. (2003). The Zone of proximal development in Vygotsky's analysis of learning and instruction, in A. Kozulin, B. Gindis, V. S. Ageyev, S. M. Miller (Eds.) Vygotsky's educational theory in cultural context (pp. 39-64). New York: Cambridge University Press

Cohen, L., Manion, L., \& Morrison, K. (2000) Research methods in education ( $5^{\text {th }}$ edition). London, Routledge Falmer.

Copland, F. (2008). Feedback in pre-service English language teacher training: discourses of process and power (Unpublished doctoral thesis). University of Birmingham, UK.

Crotty, M. (1998). The foundations of social research: meaning and perspective in the research process. London: Sage Publications.

Denzin, N. K. (1970). The research act in sociology. Chicago: Aldine.

Guba, E., \& Lincoln, Y. S. (2005). Paradigmatic controversies, contradictions, and emerging confluence. In N. K. Denzin, \& Y. S. Lincoln (Eds.), The Sage handbook of qualitative research (3rd ed., pp. 191-215). Thousand Oaks, CA: Sage

Hammond, J. \& Gibbons, P. (2005). Putting scaffolding to work: the contribution of scaffolding in articulating ESL education. Prospect, 20(1), 6-30.

Hyland, F., \& Lo, M. M. (2006). Examining interaction in the teaching practicum: Issues of language, power and control. Mentoring \& Tutoring, 14(2), 163-186.

Johnson, K. E. (2006). The sociocultural turn and its challenges for second language teacher education. TESOL Quarterly, 40, 235-257

Johnson, K. E. (2009). Second language teacher education: A sociocultural perspective. New York: Routledge. 
Palinkas, L.A., Horwitz, S.M., Green, C.A., Wisdom, J. P., Duan, N., \& Hoagwood, K. (2013). Purposeful sampling for qualitative data collection and analysis in mixed method implementation research . Administration and Policy in Mental Health and Mental Health Services Research, 42(5), 533-544. doi: 10.1007/s10488-013-0528-y.

Richardson, V. (ed) (1997). Constructivist teacher education: Building a world of new understandings. London: Falmer Press.

Schofield, J. W. (1993). Increasing the generalizability of qualitative research. In M. Hammersley (Ed.), Social research: Philosophy, politics and practice (pp. 200-225). Thousand Oaks, CA, US: Sage Publications, Inc.
Schwandt, T.A. (2015). Evaluation foundations revisited: Cultivating a life of the mind for practice. Stanford, CA: Stanford University Press.

Seng, S.H. (1997). Zone of proximal development and he world of the child. Paper presented at the Educational Research Association Conference, Singapore, November 1997.

Vygotsky, L.S. (1978). Mind in society: The development of higher mental processes (M. Cole, V.John-Steiner, S. Scribner, \& E. Souberman, Eds.). Cambridge, MA: Harvard University Press. Wood, D., Bruner, J.S., Ross, G. (1976) The role of tutoring and problem solving. Journal of Child Psychology and Psychiatry, 17, 89-100 .

\footnotetext{
${ }^{\mathrm{i}}$ In this study I will refer to the person who leads the process as the 'trainer', while some of the research participants have referred to the 'trainer' as the 'tutor'. The choice of the terms trainer or tutor is institutional and does not imply a difference in role with the Teaching Practice Group model.

ii https://www.bera.ac.uk/wp-content/uploads/2014/02/BERAEthical-Guidelines-2011.pdf?noredirect=1
} 